\title{
Compactness Effect on Bending Behavior of Cold Formed Steel Beams
}

\author{
Zeynep Yaman', Elif Ağcakoca1* \\ 1 Sakarya University, Engineering Faculty, Department of Civil Engineering, 54187 Sakarya, Turkey \\ * Corresponding author, e-mail: elifd@sakarya.edu.tr
}

Received: 09 January 2020, Accepted: 22 June 2020, Published online: 25 August 2020

\begin{abstract}
With respect to the determination of the strength of the structural steel members, first the behavior of cross section and then that of the overall member should be considered. In this study, it is aimed to determine the compactness behavior of U-shaped steel sections that exposed to minor-axis bending. Thus, the study questions whether the U-shaped cross section exhibits sufficient dimensions for the collapse mechanism to occur by aiding the moment redistribution in the structural system by supplying sufficient hinge rotation capacity. In order to investigate compactness behavior, three different channel section steel profiles are selected. Four point experimental tests are carried out to validate finite element models of the selected profiles. Upon validated finite element models, parametric studies are performed with finite element analyses. In the parametric study two steel classes, different beam lengths and cross-sectional geometries are taken as parameters. At the end of the study the plate slenderness condition required for plastic design calculated based on Eurocode3 is evaluated with the results of parametric study.
\end{abstract}

Keywords

steel U section, parametric study, finite element analysis, minor-axis bending, compactness

\section{Introduction}

Steel constructions are widely used thanks to high strength and stiffness, passing to the long openings, fast and easy installation, better recycle, uniform ductility etc. However, steel structures have some disadvantages such as low fire resistance, vulnerability against the corrosion and especially high deformation because of buckling due to small and slender cross sections [1]. Therefore the design of the steel members should be made carefully for the sake of avoiding buckling failure modes.

With respect to the determination of the strength of the structural steel members, first the behavior of cross section and then that of the overall member should be considered to avoid buckling failure. Buckling phenomenon can be defined as the structural instability that is associated with loading condition and members' slenderness. There are two main buckling failure modes may occurred on steel members; Overall (or global) buckling that characterized by a distorted, or buckled, longitudinal axis of the member; local buckling that the strength of the cross section is wagered by the buckling of a part of the cross section without any distortion on the axis of the member. In both elastic and plastic behaviors, the strength and moment capacity of the cross section are limited by the buckling effect. Thus, cross sections and slenderness conditions of steel members are become crucial for structural stability.

Compressive stresses due to the bending moments in unbraced and slender elements can cause local or global buckling. In the buckling situations, cross-section buckles before the full strength of the member is attained which is undesirable situation for structural design. Therefore, in design codes, the maximum allowable moment capacity to the plastic moment $\left(M_{p}\right)$ capacity is limited in order to satisfy the certain web and flange slenderness and lateral bracing requirements. The slenderness requirements are often referred to as "compact" limits. If all three slenderness ratios of members are less than compact limits, the section of member defines as compact sections [2]. Therefore, considering of compact limits in the evaluation of buckling situation on a structural member comes to prominent.

In order to present buckling response of structural members (columns, beams) under different loading conditions, many numerical and experimental studies were made by 
researchers [3-17]. The present study focuses on the crosssection behavior of steel channel sections subjected to minor-axis bending. The case of minor-axis bending in the U-shaped cross sections is observed in the consideration of biaxial beam bending associated with perimeter spandrel members in exterior framing lines and that in the general case of a beam column. It is potentially desirable to employ U-shaped cross sections with proportions such that sufficient structural ductility is available in the member to achieve a system-wide moment redistribution. The ability to redistribute forces plays an important role, especially in seismic design. This is also important for natural and manmade hazards in which structural robustness is crucial.

Most of the studies on structural steel beams with channel-sections are about thin walled and cold formed sections that are under the risk of buckling and about discussing the behavior of the section under both axial and bending loads. For instance; Lou and Hancock studied flexural-torsional buckling mode of channel-section beams [18]. There is a study about lateral-torsional buckling of channel-section beams loaded under minor axis in which experimental and finite strip analysis were both performed [19]. Oszvald and Dunai [20] investigate the load-carrying capacities of austenitic stainless steel channel sections with stub column tests under pure compression. Lecce and Rasmussen [21] examined ferritic stainless steel lipped channel section columns with experimental tests and numerical analysis [22]. Nonlinear instability analyses of channel-section beams subjected to minor-axis pure bending was studied by Yuan [23]. He used energy methods to derive the solutions and validated the results by using ANSYS nonlinear finite element analyses. Niu et al. [24] studied the overall buckling behavior of laterally unrestrained channel section beams with experimental tests. Theofanous et al. [25] examined the flexural performance of austenitic stainless steel channel sections exposed to moment gradient and uniform bending moment, with laterally restrained 3-point and 4-point bending tests. Kumar and Sahoo [26] studied the influence of width-to-thickness ratio and depth-towidth (aspect) ratio on the ultimate flexural strengths of channel sections bending about their minor axes. But they only covered cold formed channel-section beams in their study. Mania et al. [27] studied the post-buckling behavior of thin-walled channel cross-section members made of Fiber Metal Laminate subjected to an axial compression and they focused on the initial imperfection influence on the post-buckling response. Liang et al. [28] carried out comprehensive experimental and parametric [29] study of the local behavior of stainless steel channel sections subjected to the combined actions of axial compression and minor axis bending moment. The studies that were made in the literature generally consist of numerical or parametric investigation that validated by experimental tests. Validated numerical models provide good estimation for buckling behavior of members that is of different geometric and loading scenarios. Thus, this methodology is applied in this study to investigate U-shaped cross sections. In the study, the minor-axis bending is considered for only the positive moment when the web is in tension and the flange parts are in compression. Under a negative moment, the flange tips are not under the risk of buckling locally. Hence, the negative moment is not considered. The study consists of experimental tests for validating finite element models and numerical parametric analyses to evaluate compactness condition of members having different cross sections. Firstly finite element models are validated with four point bending test results. Subsequently, a parametric study is conducted by using the validated numerical models. The results of the parametric study are discussed in detail by comparing the values specified in Eurocode 3 and those obtained from the equation given by the elastic buckling theory. The moment rotation capacity was calculated for each cross section to define whether the cross section is compact. Finally, the study evaluate the compactness limits given in Eurocode 3.

\section{Theoretical background}

In Eurocode 3 [30], cross sections are grouped into four categories based on the yield strength of the material, width-to thickness ratio of each plate component under compression and loading arrangement [31]. The aforementioned categories are well known as plastic, compact, semi-compact, and slender and named as Class 1, Class 2, Class 3, and Class 4 in Eurocode 3, respectively. The classes are given in Fig. 1.

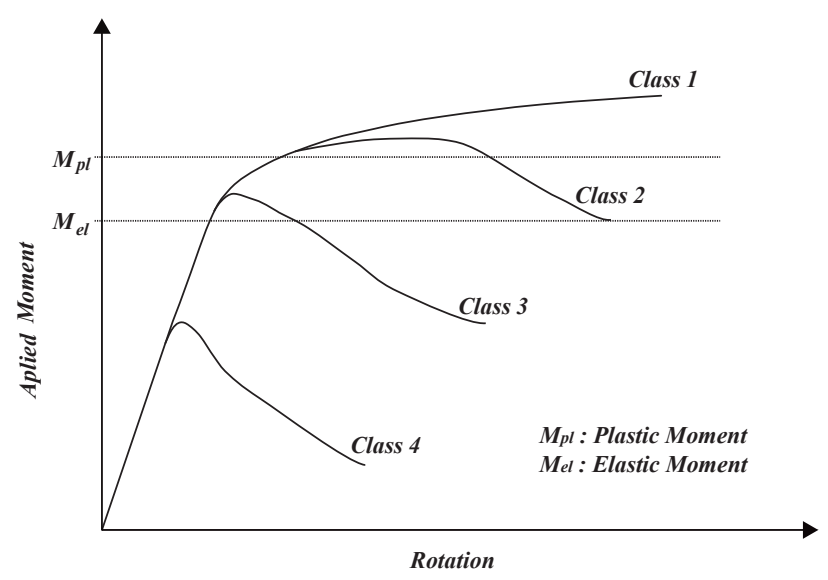

Fig. 1 The classification of cross sections according to Eurocode 3 [31] 
In the Eurocode 3, the cross-section classification is based on the plate slenderness limits for cross-sectional plate components. In the code, the limiting width-to-thickness rations are modified by a factor $\varepsilon$ that is dependent upon the material yield strength. $\varepsilon$ is defined as Eq. (1) [31];

$$
\varepsilon=\sqrt{\frac{235}{f_{y}}} .
$$

It is important to consider the plate compactness concept from the unstiffened members' viewpoint. The flanges of the U-cross section are under nonuniform flexural compression loading in minor-axis bending, and thus they behave as unstiffened members. Given this type of behavior, the plate slenderness is calculated as $\lambda_{c r}=0.46$ with the onset of plate hardening [32]. The slenderness is defined as follows by Haaijer and Thürlimann [32].

$\lambda_{c r}=\sqrt{\frac{F_{y}}{F_{c r}}}$,

where,

$$
F_{c r}=k \frac{\pi^{2} E}{12\left(1-v^{2}\right)\left(\frac{c}{t}\right)^{2}} .
$$

Here, $E$ and $v$ denote the material's elastic modulus and Poisson's ratio, respectively. Furthermore, $k$ defines the plate-buckling coefficient in which the value depends on the plate boundary conditions, stress distribution around the loading edge, and plate aspect ratio. When the equation is solved for the width-to-thickness ratio $(c / t)$ by taking $E=200 \mathrm{GPa}$, we obtain the following expression:

$$
\frac{c}{t}=195,574 \sqrt{\frac{k}{F_{y}}} .
$$

The elastic plate buckling coefficient, $k$, is defined as 0.425 and 1.277 for the pinned and fixed cases, respectively. Flange plates are elastically restrained by the web plate, and the true boundary condition lies between the upper and lower bound limits of pinned or fixed plate edges. It is not possible to specifically address the flange support as pinned and fixed, and thus we can consider the two extreme values for the present case of the channel section flange. Thus, the width-to-thickness ratio is derived for two limiting support conditions of the flange web junction as given in Table 1 .

Additionally, values of the $\mathrm{c} / \mathrm{t}$ ratio for each steel class are calculated and listed in the table. It is expected that the elastic plate slenderness values obtained from elastic
Table 1 Plate slenderness, $c / t$, formulas and corresponding values [32]

\begin{tabular}{cccccc}
\hline & \multicolumn{2}{c}{ Plate Bucklink Theory } & \multicolumn{2}{c}{ Eurocode 3 } \\
& & Pinned-support & Fixed-support & Class 1 & Class 2 \\
\hline \multirow{2}{*}{$\mathrm{c} / \mathrm{t} \leq$} & S 235 & 8.32 & 14.42 & 9 & 10 \\
& S355 & 6.77 & 11.73 & 7.29 & 8.1 \\
\hline
\end{tabular}

plate buckling theory are in close proximity with the slenderness values given in Table 1. The uncertainty arises from the way to define the actual web-flange conjunction, namely as pinned or fixed.

\section{Experimental study}

\subsection{Material properties}

In order to determine the stress-strain diagram of the steel members, three coupon samples were cut from the test elements and prepared according to ASTM E8 [33]. The coupon samples are given in Fig. 2. Three samples which were named as Tensile Test Sample1 (TTS \#1), Tensile Test Sample2 (TTS \#2), Tensile Test Sample3 (TTS \#3) were tested with axial tensile test and stress-strain graphs were obtained for each of samples (Fig. 2).

\subsection{The experimental test setup}

In this study, three test specimens were produced by keeping $b_{f} / d$ ratio constant in determining the behavior of elements placed on weak axis under bending effect. The $L / b_{f}$ ratio of the test samples changes regularly. Four point loading tests were performed on three test elements. Samples were prepared as $1000 \mathrm{~mm}$ and $500 \mathrm{~mm}$ between supports. For the test specimens with a length of $500 \mathrm{~mm}$, the distance between the loads is $200 \mathrm{~mm}$ and for the 1000 $\mathrm{mm}$ test sample, the distance between loads is determined as $300 \mathrm{~mm} .80 \times 15 \times 500$ spreader beam was used to apply the load evenly on the test element. Two $80 \times 10 \times 50$ $\mathrm{mm}$ steel bars were used to ensure load transfer from the spreader to the beam. Rubber pads were used to prevent the damage from the specimen. The experimental setup and boundary conditions of the test specimen are shown
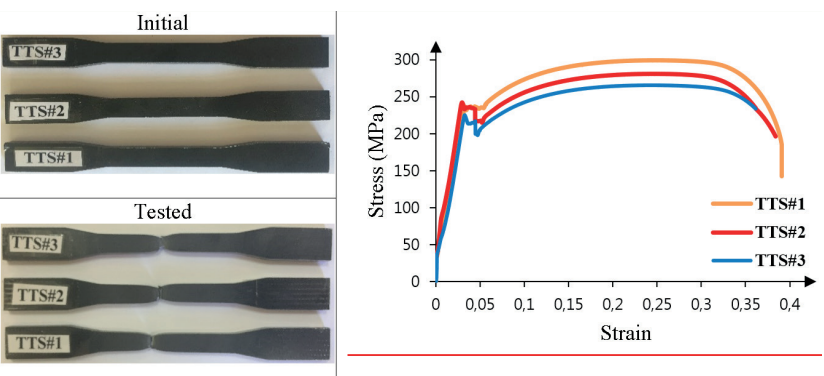

Fig. 2 View of test setup and schematic view of testing 
in Fig. 3. Information on the dimensions and mechanical properties of the test specimens are given in Table 2. Fig. 4 with drawing; $d$ : profile width, $b_{f}$ : profile flange length, $c$ : profile flange length after removing the thickness, $t$ : profile thickness is expressed.

Experiments were performed under four-point loading that created a fixed moment region. This is important because the behavior under the effect of pure flexure can be examined by eliminating shear-stress-related deformations.

\section{Finite Element Models of the samples}

Finite element models of the specimens that are validated with experimental test results are used for the parametric analysis. In this part of the study, detailed information on the assumptions in modeling steps and the techniques used in the finite element analyses are presented. A commercial finite element analysis software package that is widely used in many engineering scientific studies, ABAQUS version 6.8, was used in the study [34]. In the analyses, both material and geometric nonlinearities were

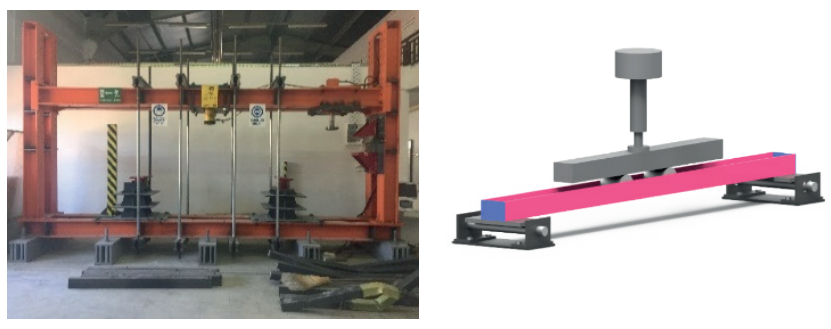

Fig. 3 View of test setup and schematic view of testing

Table 2 Dimensional and material properties of test specimens

\begin{tabular}{lcccccc}
\hline Name & $\begin{array}{c}\text { Cross Section } \\
\left(d, b_{f}, t\right) \\
(\mathrm{mm})\end{array}$ & Span & $b_{f} / d$ & $L / b_{f}$ & $\begin{array}{c}\text { Yield } \\
\text { Stgth }\end{array}$ & $\begin{array}{c}\text { Tensile } \\
\text { Stgth }\end{array}$ \\
& $(\mathrm{mm})$ & & & $(\mathrm{MPa})$ & $(\mathrm{MPa})$ \\
\hline Specimen \#1 & $105 \times 50 \times 2.5$ & 1000 & 0.5 & 20 & 245 & 290 \\
Specimen \#2 & $105 \times 50 \times 2.5$ & 500 & 0.5 & 10 & 237 & 284 \\
Specimen \#3 & $70 \times 35 \times 2.5$ & 500 & 0.5 & 5 & 230 & 275 \\
\hline
\end{tabular}

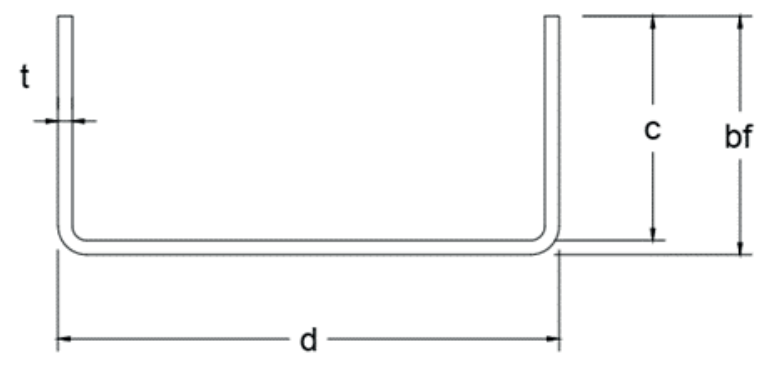

Fig. 4 Abbreviations on the cross section considered. Unstable behavior due to local buckling was present in the analyses, and thus the Riks-Wempner incremental solution technique was preferred, given its ability to catch the critical points such as buckling on the equilibrium path. It is considerably important to catch the critical points in this type of compactness study as the achievement of the plastic moment capacity is limited with the points. In the study, S235-S355 mild steel with the elastic-perfectly-plastic model was used by introducing the von-Mises failure surface change based on the isotropic hardening rule. Strain hardening and residual stresses were ignored. The Poisson's ratio was assumed as 0.3 and the modulus of elasticity is taken as $200 \mathrm{GPa}$. True stress and strain values were calculated and implemented in the model. The aforementioned two steel classes, S235-S355, were selected owing to their wide usage in civil engineering.

\subsection{Mesh and support conditions}

Channel cross sections were meshed with shell finite elements positioned along the middle surface on the cross-sectional constituent plate components. Beams were seeded with finite elements in which the geometrical dimensions exhibit an aspect ratio of one. The S4R nonlinear and finite strain shell element from the ABAQUS element library was used. The S4R shell element considers shear deformations $[35,36]$. To exhibit thin shell behavior, both the strain method specified in Macneal [37] and reduced integration were used in the formulation of the element. This type of element was selected as it yielded reliable results in previous validation studies [38]. The sensitivity of the numerical model to the mesh density was also examined using different mesh densities. There were no significant differences in the results when different mesh densities were used. Finally, a shell element as close as possible to $1 \times 1 \mathrm{~cm}$ was used to maintain the element's aspect ratio value of one. Flanges and the web plate shared the same nodes at the connection interface with identical degrees of freedom. Supports were assigned to the nodes at the web plate. Support conditions were only defined at the web plate on both edges as roller supported at an edge and simply supported at the other edge. Point loads were also assigned at the nodes of the web to create a line form similar to that in the real experimental test. Constructed finite element model is shown in Fig. 5.

$\mathrm{U} 1=$ displacement in the $\mathrm{x}$ axis, $\mathrm{U} 2$ = displacement in the $\mathrm{y}$ axis, $\mathrm{U} 3$ : displacement in the $\mathrm{Z}$ axis are represented at Fig. 5. 


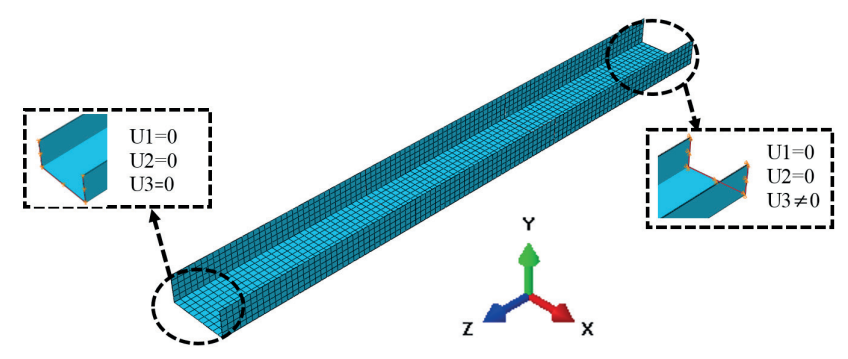

Fig. 5 Finite element model of the test specimen

\subsection{Validation of the models}

The study uses finite elements modeling techniques, and thus it is considerably important to compare the results obtained from the constructed numerical model and those obtained from the experimental study. The validation process should be made to achieve more reliable results and it is widely applied in numerical studies that made in the literature [39-41].

To examine geometrical and material nonlinearities and imperfections by finite element modeling, the inclusion of an imperfection field into the model is typically advised. The imperfection field is used to perturb the perfect geometry of the model. When the imperfection field is ignored, the model stays in an artificially perfect geometry throughout the loading. It is a mathematically acceptable equilibrium condition, and thus it is possible to obtain a solution from finite element analysis with its initially perfect geometry. However, this does not correspond to a physical meaning as any disturbance or imperfection can convert the equilibrium condition to inaccessibly practical cases.

To avoid the cases that are mathematically possible (although not possible in reality), it is necessary to add an acceptable amount of geometrical imperfections to the finite element models. An approach to implement imperfection involves adopting a geometry similar to that of the first two buckling modes [42] (Fig. 6(a, b)). It is observed from the linearized eigenvalue buckling analyses performed with ABAQUS that the governing mode of instability in the minor-axis U-shaped members involves localized buckling shapes within the flange. Thus, sinusoidally varying imperfections with a half wavelength of $b_{f} / 2$ are used in conjunction with a magnitude corresponding to the maximum allowable fabrication imperfection permitted by the American Welding Society [44], namely a value of $b_{f} / 100$. Fig. 6(c). illustrates the sinusoidally varying imperfection geometry.

The finite element model was made without considering the radius (at the point of junction) (FEM \#1) and with the radius (FEM-R\#1). When load-displacement curves were compared, it was observed that the load-displacement

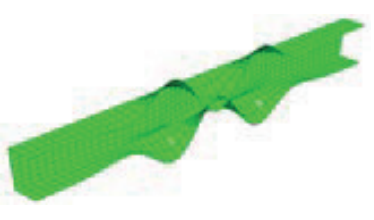

(a)

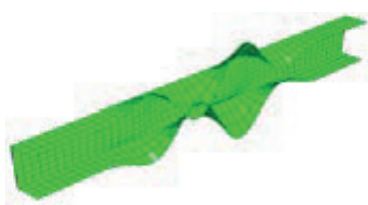

(b)

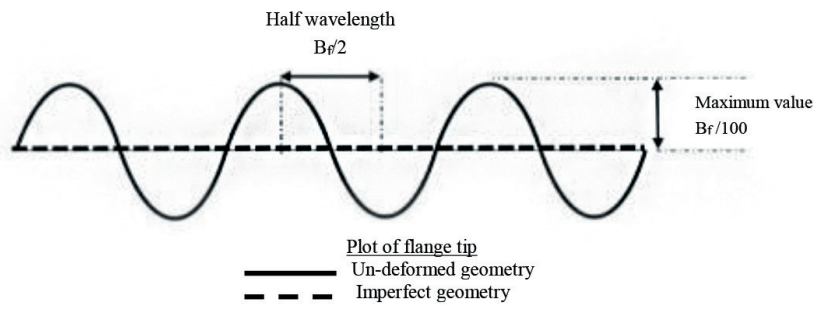

(c)

Fig. 6 Implementation of imperfect geometry at the flange tips $[42,43]$ Buckling mode shape-MOD1, b) Buckling mode shape-MOD2,

c) Idealized sinusoidally varying imperfection geometry

curve of the model where radius was not taken into account was more approximate to the load displacement curve of the experiment (Fig. 7).

Experimental studies were performed on 3 samples. At the end of the study, pre- and post-test pictures of the samples are shown in Fig. 8. End plates in the test samples were used to simulate the boundary conditions of the $\mathrm{U}$ profile in the structure. These boundary conditions are defined in the finite element model by the degrees of freedom of the cross-section nodes. It is shown in Fig. 5.

Three minor-axis bending experiments are reproduced as a numerical model and the structural responses obtained from numerical analysis of the models are subsequently compared with those of experimental tests. Loaddisplacement graphics are plotted for both numerical and experimental test results in Fig. 9. Additionally, ratios of the maximum load and corresponding deflection values are given in Table 3 . The validation results indicate that proposed numerical modeling steps reflect the ultimate force and maximum deflection with a $+4 \%$ and $+13 \%$ difference, respectively. When the general response in the experiment is compared with that observed in the numerical analysis, the findings indicate that the results agree.

Three experimental test samples are considered sufficient to validate the numerical modeling steps as the three tests exhibited different cross sections, different flange slenderness values, and different beam lengths. Based on the results, it is concluded that the proposed modeling strategies yield reliable results for the parametric studies that are to be conducted. In addition, the deformation shapes of the specimens, which were obtained after experimental tests and numerical analyses, are nearly overlapped as shown in Fig. 10 . 


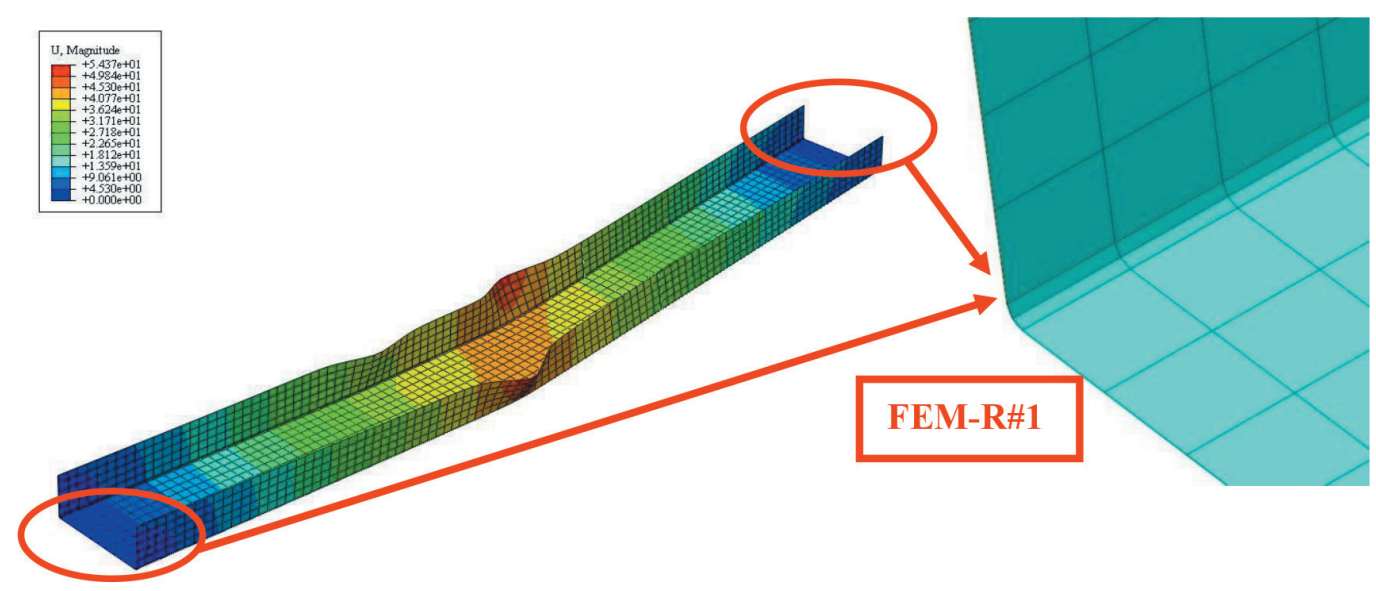

FEM-R\#1

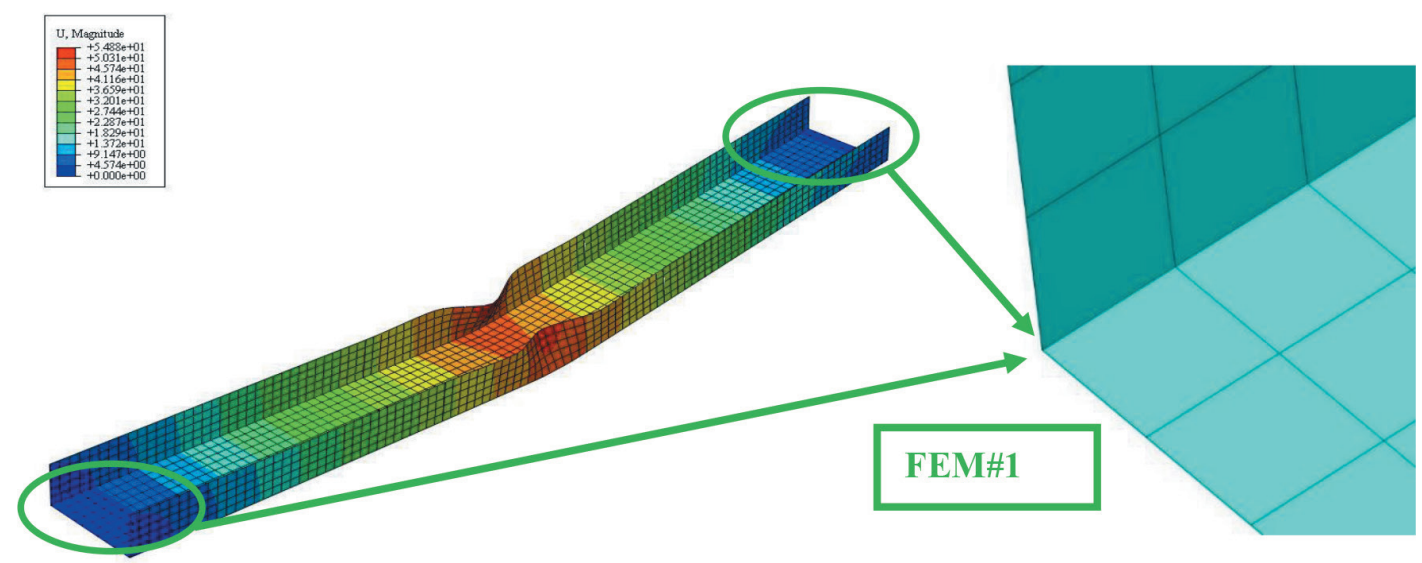

FEM\#1

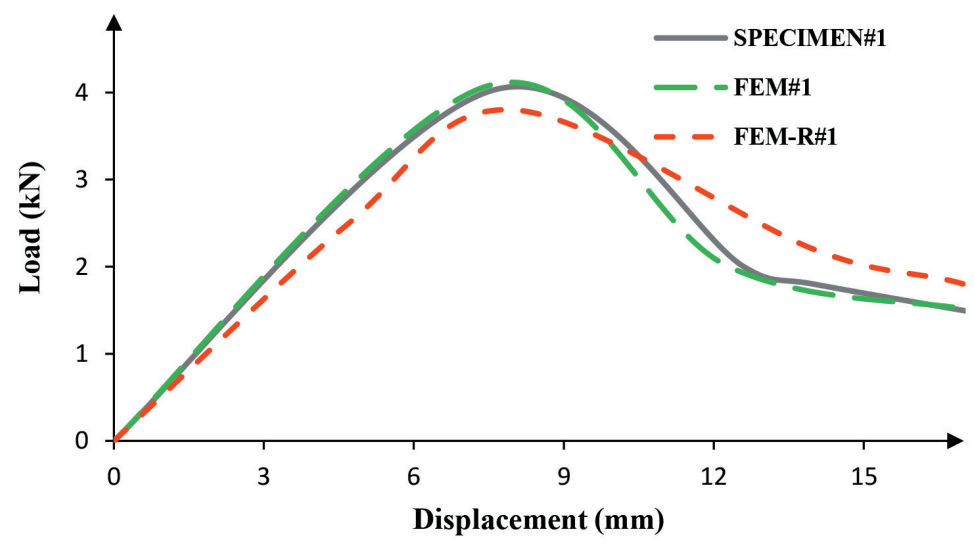

Fig. 7 Comparison of the considering of radius situation in numerical model
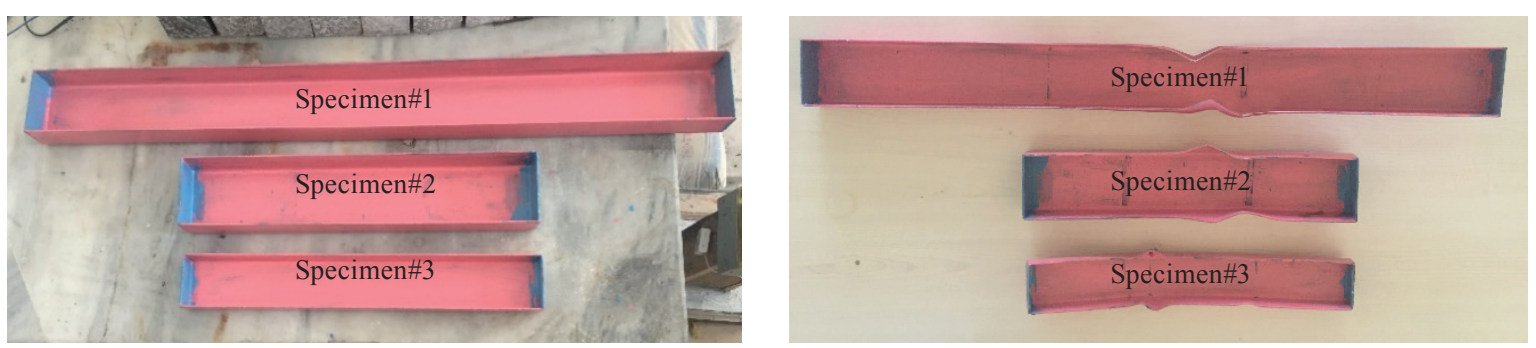

Fig. 8 Pre-visual and post-test visuals of test elements 

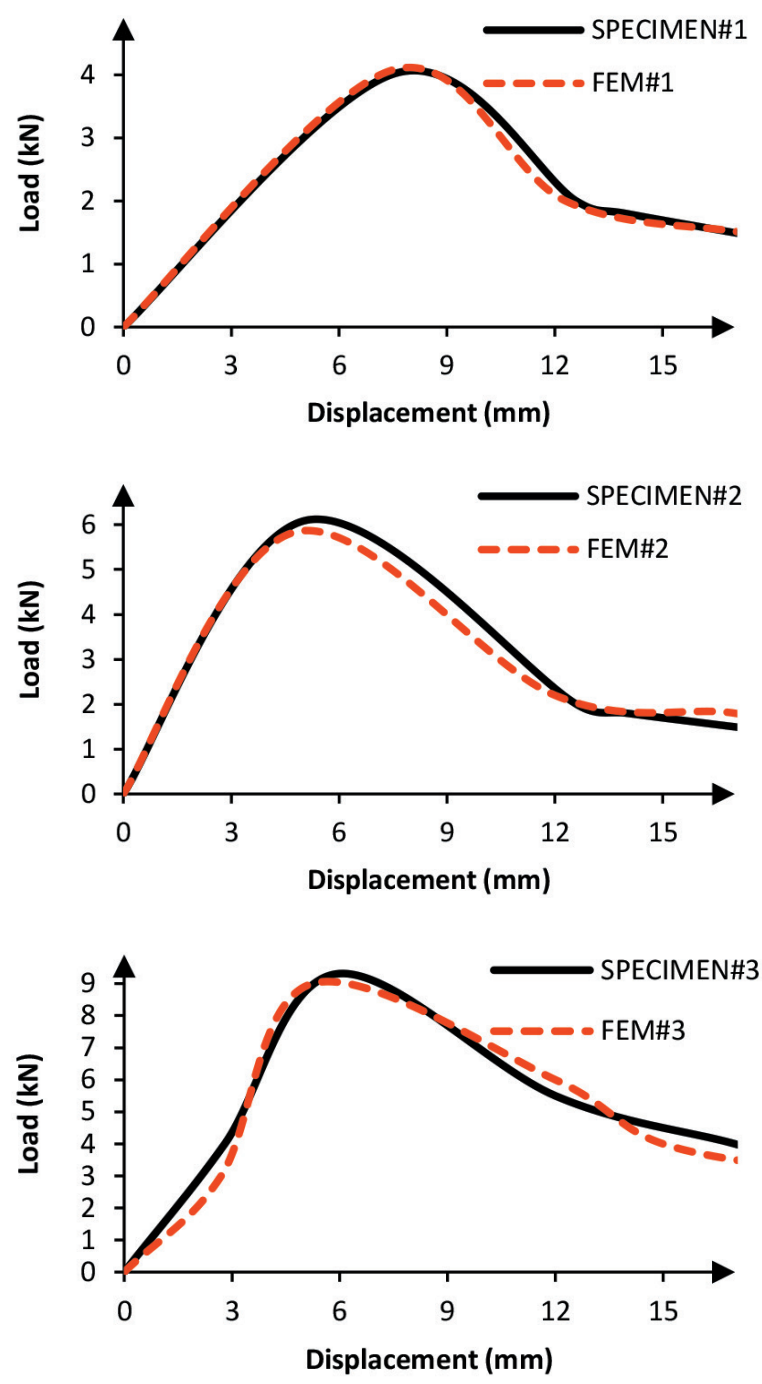

Fig. 9 Validation results of numerical models

Table 3 Comparison of finite element modeling results and experimental result

\begin{tabular}{lcccccc}
\hline & \multicolumn{3}{c}{ Ultimate Load (kN) } & \multicolumn{3}{c}{ Maximum Deflection (mm) } \\
Name & PTest & PFEM & $\begin{array}{c}\text { PTest / } \\
\text { PFEM }\end{array}$ & $\Delta$ Test & $\Delta$ FEM & $\begin{array}{c}\Delta \text { Test / } \\
\Delta \text { FEM }\end{array}$ \\
\hline Specimen \#1 & 4.03 & 4.08 & 0.99 & 7.60 & 7.50 & 1.01 \\
Specimen \#2 & 9.30 & 9.00 & 1.03 & 5.10 & 4.80 & 1.06 \\
Specimen \#3 & 6.10 & 5.84 & 1.04 & 5.90 & 5.24 & 1.13 \\
\hline
\end{tabular}

\section{Parametric study}

Upon validation of the FE models, parametric studies were carried out to study the buckling behavior of channel-section beam over a wide range of key parameters, including the cross-sectional aspect ratio $\left(b_{f} / d\right)$, unbraced length to cross-sectional depth ratio $\left(L / b_{f}\right)$ and the flange slenderness ratio $\left(c / t_{f}\right)$. Web slenderness ratio $\left(h / t_{w}\right)$ was kept constant in the parametric study. The parametric study was made for both S235 and S355 class steels. The compactness level is determined by calculating the rotation capacity $(R)$ for each cross section. To claim a cross section as a compact cross section, it should exhibit at least an $\mathrm{R}$ value of three [43]. The rotation capacity used in the study is defined by $R=w\{(\theta 2 / \theta 1)-1\}$ as given in the ASCE [44]. In the equation, $\theta 2$ defines the rotation value at which the moment capacity of the cross section is less than its plastic moment capacity in the $M_{n} / M_{p}$ diagram. Thus, it is crucial to determine the loading and specifically the unloading path to calculate $R$. In the $\theta / \theta_{p}$ graph, $\theta 1$ denotes the theoretical rotation angle for the moment at which the plastic moment capacity calculated based on the elastic beam stiffness is reached. The degree of the ductile behavior is graphically defined in Fig. 11. When the rotation value for no seismic design of steel structures is considered as three $(R=3)$, it is accepted that the structure behaves in a sufficiently ductile manner [45], and thus the available compactness provisions were determined based on the $R$ value [45-49].

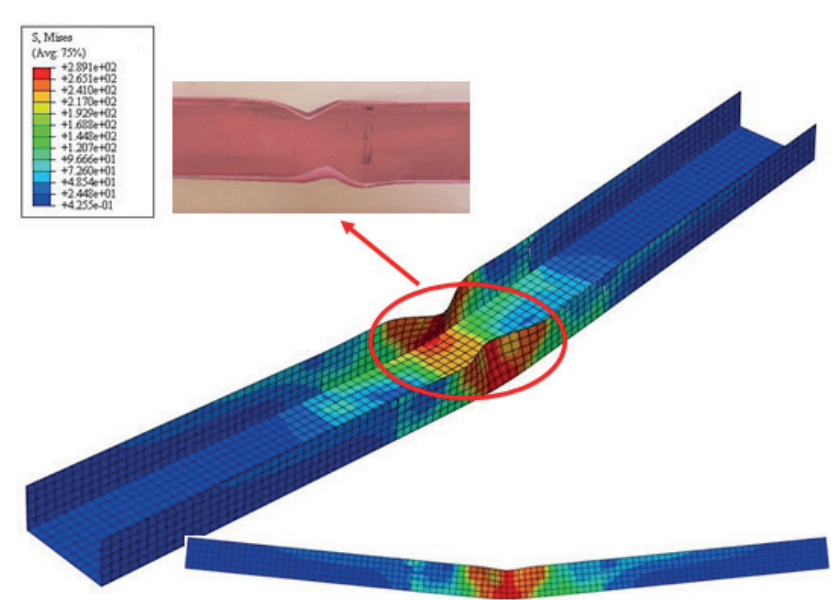

Fig. 10 Comparison of experimental and numerical deformation shapes

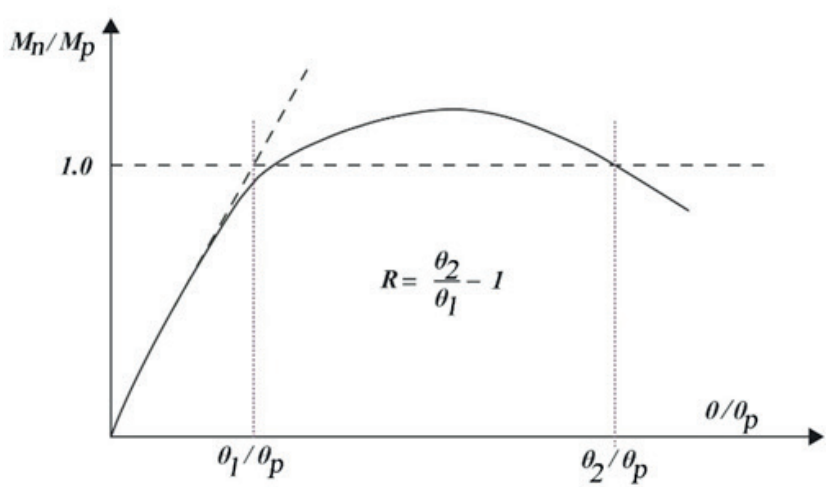

Fig. 11 Graphical representation of moment rotation value, $R[50]$ 


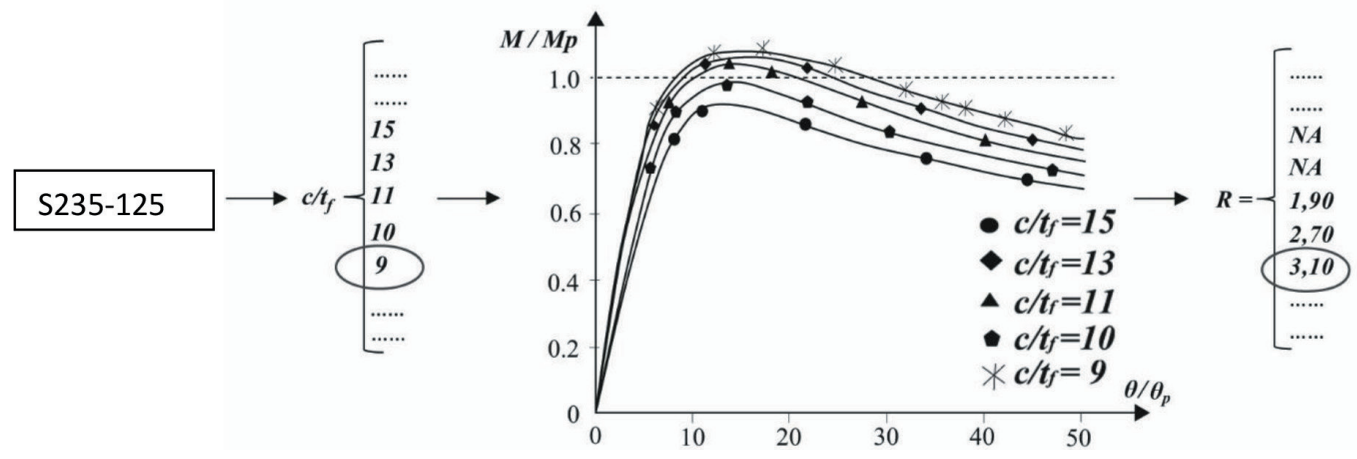

Fig. 12 Steps taken to determine the moment rotation value of at least three [50]

While arriving at individual plate slenderness limits for compact flange response, the ratio $c / t_{f}$ is varied for a fixed combination of the other two parameters, namely $b_{f} / d, \mathrm{~L} / b_{f}$ until a moment rotation capacity of at least $R=3$ is achieved (Fig. 12). The values calculated by the existing equation as given in Eurocode 3 are also given in the same tables. In the Table 4 and Table 5, $\mathrm{C} 1$ and $\mathrm{C} 2$ indicate the limiting plate slenderness values for Class 1 and Class 2, respectively.

\section{Discussion of the results}

\subsection{Numerical result-based flange slenderness limit versus that obtained from Eurocode 3}

There are a few cross sections in which Eurocode 3 yields a high slenderness limit value of 14 . However, when the identical cross sections were observed that the compactness limits are smaller values than the compactness limits of Class 1 and Class 2 given in Eurocode 3. This is the case for beams with $b_{f} / d$ values of $1,0.8,0.6$. Slenderness values calculated based on Eurocode 3 are conservative only for cross sections with $b_{f} / d=0.4$ when compared with those obtained from numerical analysis (Table 5).

Numerical analysis allows a low slenderness ratio for cross sections with high $b_{f} / d$ values to meet the compactness criteria. This is practical because the region of the flange that is under compression is far from the web junction, and thereby is in keeping with support for the flange. When $b_{f} / d$ is lower than the neutral axis shift close to the web, the flange starts to behave in a manner similar to a supported plate. Thus, the shift permits a higher slenderness ratio for cross sections with $b_{f} / d=0.4$. (Fig. 13)

\subsection{Effect of the steel yield stress, Fy, on the flange compactness limit}

The aim involved investigating the effect of yield strength on the flange compactness limit by assuming that the yield strength values of the steel are $235 \mathrm{MPa}$ and $355 \mathrm{MPa}$. All the other parameters are considered constant, and it is observed that the $c / t_{f}$ ratio decreases when the yield strength increases. This is coherent with the Eurocode 3 as $c / t_{f}$ and Fy are inversely proportional to each other in Eurocode 3. The results for the effect of yield strength are shown in Fig. 14 for a representative study group.

\subsection{Improving the equations given in the Eurocode 3}

The flange slenderness values calculated using the elastic buckling theory and tabulated in Table 1 are in good agreement with those calculated using the equations for Eurocode 3. As observed in Table 1, the plate slenderness values are obtained by assuming that an edge of the plate is simply supported or fixed. Additionally, it can be argued that Eurocode 3 potentially yields more conservative values as it assumes that the loaded edge is under uniform compression, and this corresponds to the most unfavorable loading case. However, numerical analysis indicates that this is not true as the flange slenderness values observed in the study are considerably more conservative than those in Eurocode 3. The aforementioned differences create a risk in the design if the design based on the existing Eurocode 3. The reason is essentially that the neutral axis of cross sections does not always lie within the web-flange conjunction and instead shifts through the flange. In this case, the compression region of the flange behaves as an unstiffened plate (Fig. 13).

Potentially, the use of the limiting plate slenderness mentioned in Eurocode 3 gives accurate results when the neutral axis is located on the web of the channel section under minor-axis bending. If the neutral axis is located far from the web, then the new plate slenderness, $\lambda_{c}$, which defines the onset of hardening, should be defined. The new plate slenderness should be calculated as the average between the lower and upper bounds. Thus, the plate slenderness value of $\lambda_{c}=0.315$ is calculated by averaging the lower bound $\lambda_{c}=0.46$ (unstiffened plate) and upper bound $\lambda_{c}=0.17$ given by Haaijer and Thürlimann [32]. Thus, plate slenderness ratio for unstiffened plate should be as follows: 


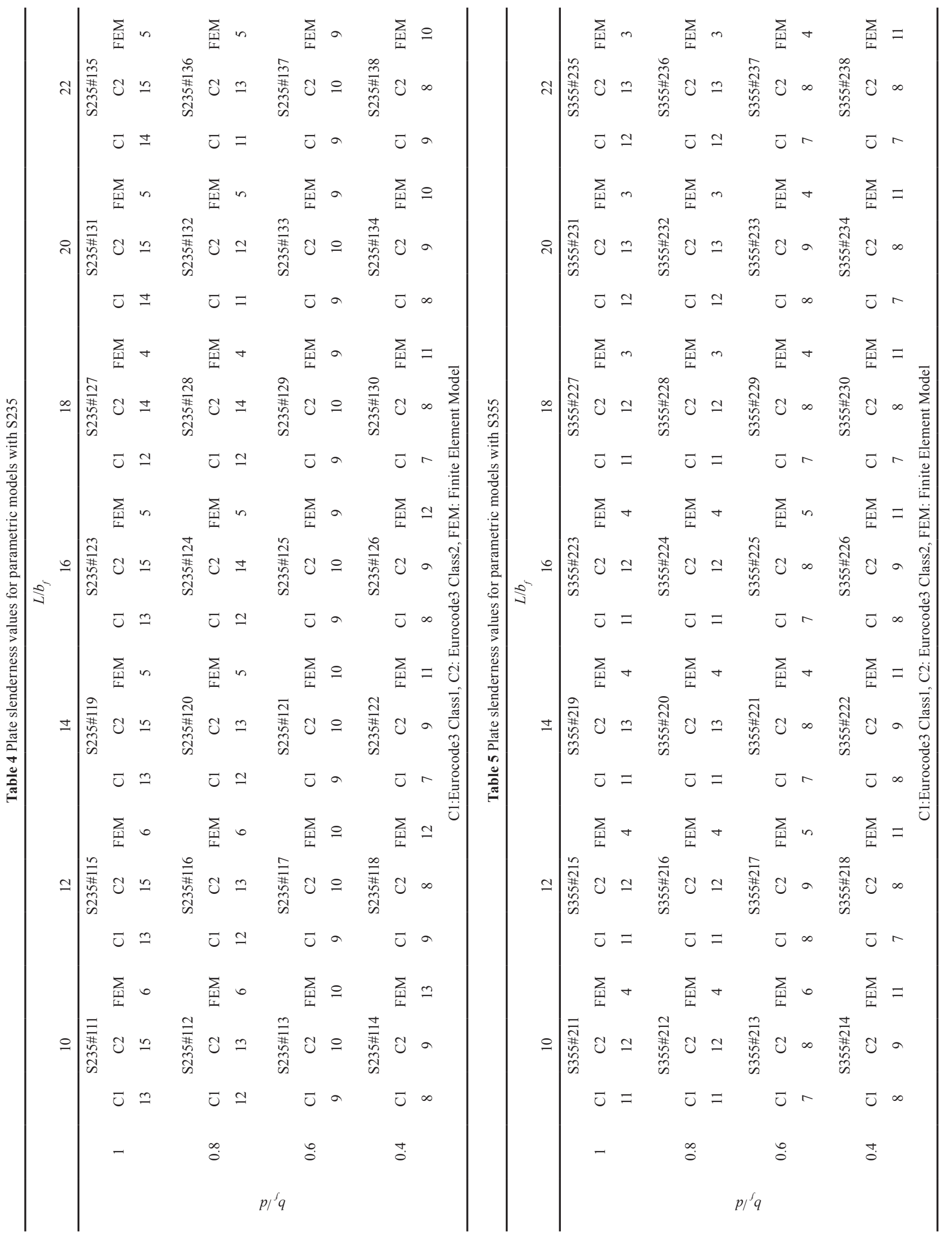




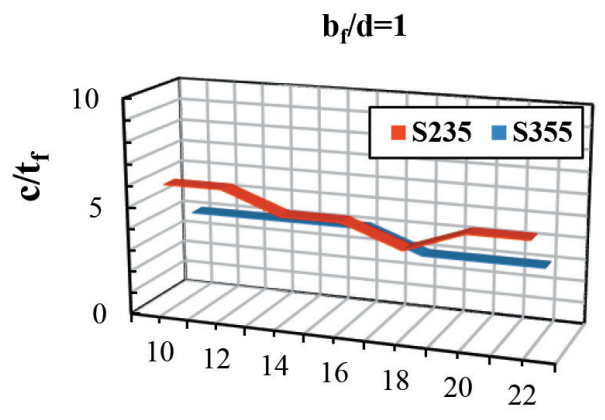

$\mathbf{L} / \mathbf{b}_{\mathbf{f}}$

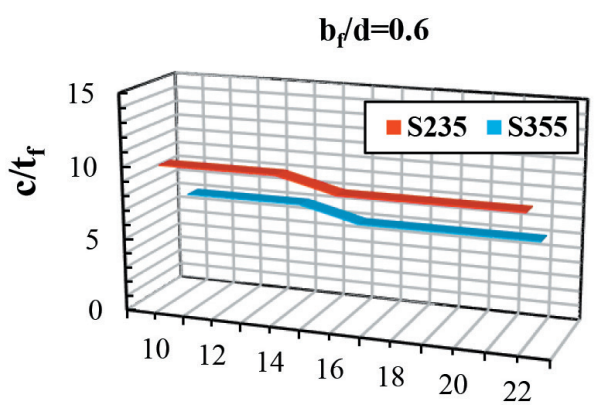

$\mathbf{L} / \mathbf{b}_{\mathbf{f}}$

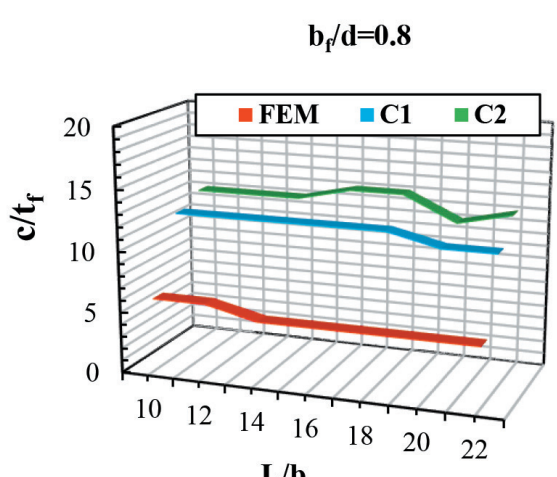

$\mathbf{L} / \mathbf{b}_{\mathrm{f}}$

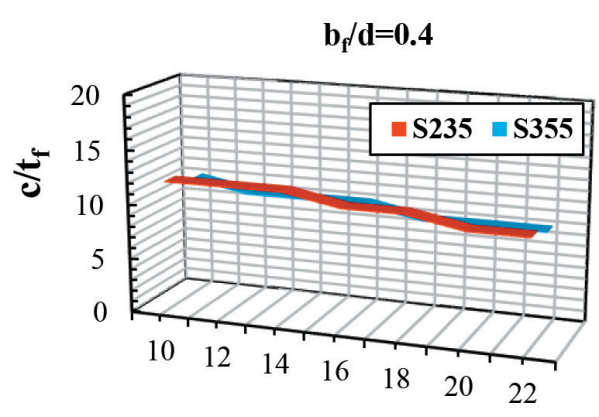

$\mathbf{L} / \mathbf{b}_{\mathbf{f}}$

Fig. 14 Effect of yield stress on the flange compactness limit

$\mathbf{b}_{\mathrm{f}} / \mathbf{d}=\mathbf{1}$

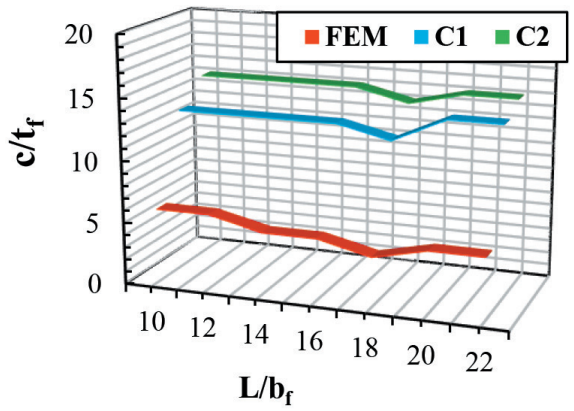

$b_{f} / d=0.6$

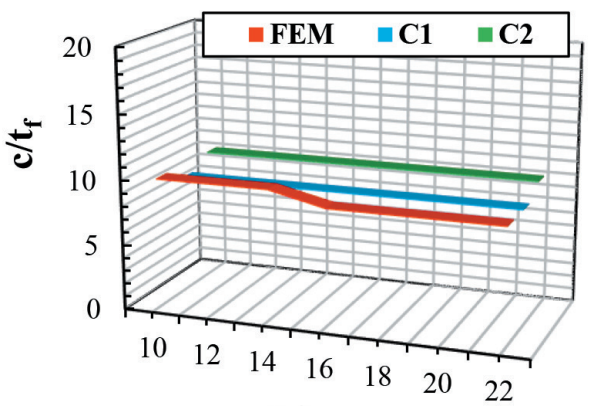

$\mathbf{L} / \mathbf{b}_{\mathbf{f}}$

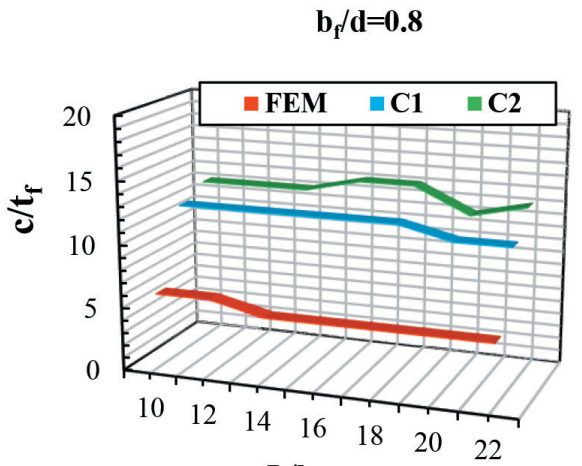

$\mathbf{L} / \mathbf{b}_{\mathbf{f}}$

$b_{f} / d=0.4$

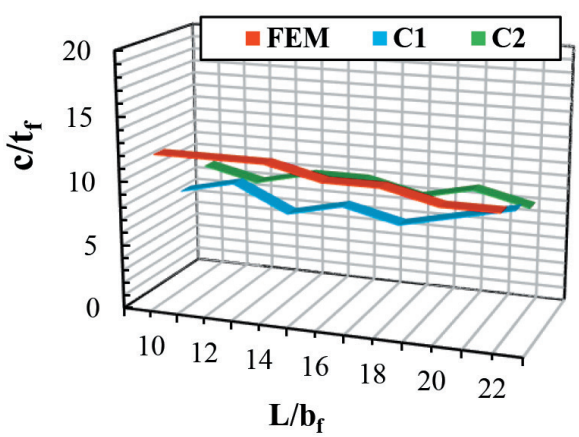

Fig. 13 Flanges under compression limit, S235 
$\frac{c}{t}=5.7 \varepsilon$

for stiffened plate should be as follows

$\frac{c}{t}=9.9 \varepsilon$

Here $\varepsilon=\sqrt{235 / \sqrt{F_{y}}}$.

If Table 1 is updated with these equations, then the values of Eurocode 3 are reliable and do not conflict with numerical results (Table 6). However, it will be seen to coincide with the FEM results. $\alpha$ is defined that the ratio of the pressure zone length to the pull zone length in Eurocode 3.

When the results of Tables 4 and Table 5 are compared with Table 6, the flanges have unstiffened plate slenderness in cross sections where the $b_{f} / d$ ratio is 0.6 and greater, and the flanges in the cross sections where the $b_{f} / d$ ratio is 0.4 and smaller exhibit compact behavior in the stiffened plate slenderness. However, when the Flanges Slenderness are examined in Table 6, it is seen that Eurocode 3 accepts flanges as stiffned plates both Class 1and Class 2 .

\section{Conclusions}

This paper presents parametric studies to examine plate slenderness conditions required for plastic design of channel section steel profiles. In order to obtain reliable numeric results, finite element models of profiles were validated according to experimental results obtained from four point bending tests. Upon validated FE models, parametric studies were carried out using two steel classes, different beam lengths and cross-sectional geometries. The following conclusions are drawn:

It is observed that, with the increase of $b_{f} / d$ ratio, the flange slenderness values which will provide the rotational capacity required for plastic design decrease nearly $60-70 \%$ With increasing steel yield strength, the flange slenderness values, which will provide the necessary rolling capacity for plastic design, reduce about $10-35 \%$.

It is calculated that while the $b_{f} / d$ ratio is 0.6 , there is a variation on $10-15 \%$ between flange slenderness results of FE analysis and plate slenderness values of Eurocode 3. As the $b_{f} / d$ ratio increases ( 0.8 and 1$)$ the variation ranges between $50-85 \%$, and as the bf/d ratio decreases $(0.4)$, the variation ranges among $20-30 \%$.

By looking at the plate slenderness values obtained as a result of the parametric study, it can be said that if the $b_{f}$ $/ d$ ratio is 0.6 and greater in a bending effect $u$ profile, the flanges of $U$ will exhibit stiffened plate behavior, and if it is less than 0.6, it will exhibit stiffened plate behavior.
The $b_{f} / d$ 's turning point value changed the behavior can be analyzed another study by changing in $b_{f} / d$ ratio at closer intervals.

According to the results, it is observed that the plate slenderness values given in Eurocode 3 are much safer than the slenderness ratio limits for channel sections that exposed to minor-axis bending. Thus, if the values depicted in Eurocode 3 are used, then the cross sections do not reach their plastic capacities without buckling, as proposed.

Based on the plate buckling theory, the results obtained with the recommended plate slender limit equations (Eq. (5) and Eq. (6) gave results in the range of slender values obtained with FEM. This shows that, in plates supported from one end to the other cross section of the profile, plate slenderness should be nearby $\lambda_{c}=0.315$

When the solution steps of the differential equations given for buckling of plates in the literature are applied for U-section; two formulas were obtained according to the fact that the connection of the head plates to the body is considered as fixed or built-in bearing. The numerical analysis results and calculations that are obtained using the elastic buckling theory indicated that the reason for the unreliability is attributed to the plate support. The presence of different boundary conditions should be investigated as the plate slenderness, $\lambda_{c}$, is extremely sensitive to the support condition. Thus, a stiffened plate and an unstiffened plate exhibit different behavior on reaching the plastic moment.

Finally, it can be clearly seen that geometric properties affect the buckling behavior of channel section steel profiles substantially. In the present study only two widely used steel classes are considered. It is necessary to perform additional experimental and numerical studies with different types of steel class and different types of loadings such as a three-point load.

Table 6 Updated slenderness values for unstiffened plates [32]

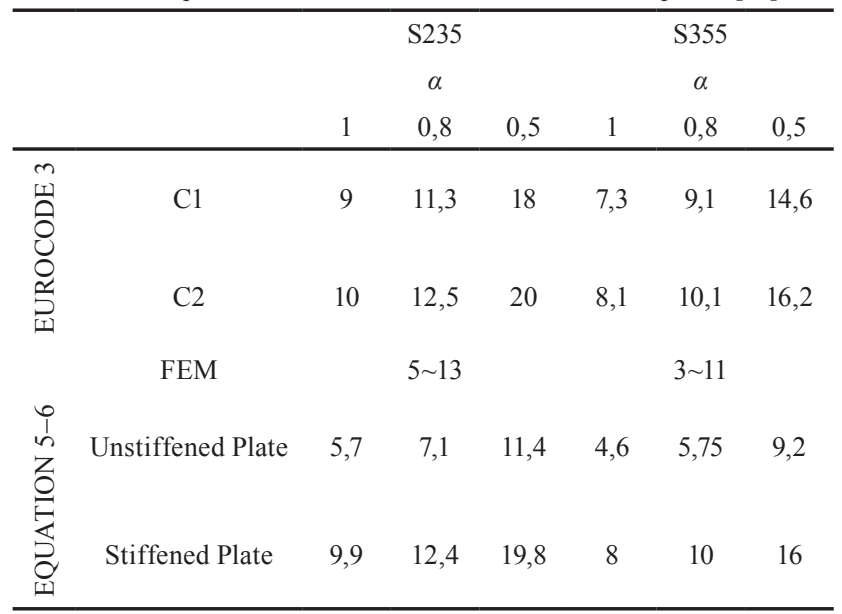




\section{References}

[1] Altunisik, A. C., Ates, S., Husem, M., Genc, A. F. "Collapse of steel cantilever roof of tribune induced by snow loads", Steel and Composite Structures, 23(3), pp. 273-283, 2017.

https://doi.org/10.12989/scs.2017.23.3.273

[2] Barth, K. E., White, D. W., Righman, J. E., Yang, L. "Evaluation of web compactness limits for singly and doubly symmetric steel I-girders", Journal of Constructional Steel Research, 61(10), pp. 1411-1434, 2005

https://doi.org/10.1016/j.jcsr.2005.03.002

[3] Kudzys, A., Lukoševičienè, O., Baltrukènaitė-Kroškienė, I. "Structural safety of rolled and welded beams subjected to lateraltorsional buckling", Journal of Civil Engineering and Management, 16(2), pp. 172-178, 2009.

https://doi.org/10.3846/jcem.2010.18

[4] Couto, C., Vila Real, P., Lopes, N., Zhao, B. "Numerical investigation of the lateral-torsional buckling of beams with slender cross sections for the case of fire", Engineering Structures, 106, pp. 410-421, 2016.

https://doi.org/10.1016/j.engstruct.2015.10.045

[5] Saoula, A., Meftah, S. A., Mohri, F., Daya, E. M. "Lateral buckling of box beam elements under combined axial and bending loads", Journal of Constructional Steel Research, 116, pp. 141-155, 2016. https://doi.org/10.1016/j.jcsr.2015.09.009

[6] Shi, G., Xu, K., Ban, H., Lin, C. "Local buckling behavior of welded stub columns with normal and high strength steels", Journal of Constructional Steel Research, 119, pp. 144-153, 2016. https://doi.org/10.1016/j.jcsr.2015.12.020

[7] Huang, Y., Young, B. "Experimental investigation of coldformed lean duplex stainless steel beam-columns", Thin-Walled Structures, 76, pp. 105-117, 2014. https://doi.org/10.1016/j.tws.2013.11.006

[8] Ibrahim, S. A., Dessouki, A. K., El-Saeed, S. A. "Lateral buckling behavior and strengthening techniques of coped steel I-beams", Journal of Constructional Steel Research, 108, pp. 11-22, 2015. https://doi.org/10.1016/j.jcsr.2015.02.003

[9] Ning, K., Yang, L., Yuan, H., Zhao, M. "Flexural buckling behaviour and design of welded stainless steel box-section beam-columns", Journal of Constructional Steel Research, 161, pp. 47-56, 2019.

https://doi.org/10.1016/j.jcsr.2019.06.017

[10] Bešević, M., Prokić, A., Landović, A., Kasaš, K. "The Analysis of Bearing Capacity of Axially Compressed Cold Formed Steel Members", Periodica Polytechnica Civil Engineering, 61(1), pp. 88-97, 2017.

https://doi.org/10.3311/PPci.8836

[11] Aktas, M., Balcioglu, H. E. "Buckling behavior of pultruded composite beams with circular cutouts", Steel and Composite Structures, 17(4), pp. 359-370, 2014. https://doi.org/10.12989/scs.2014.17.4.359

[12] Secer, M., Uzun, E. T. "Inelastic Ultimate Load Analysis of Steel Frames Considering Lateral Torsional Buckling under Distributed Loads", Periodica Polytechnica Civil Engineering, 63(3), pp. 872$881,2019$.

https://doi.org/10.3311/PPci.13513
[13] Mahi, I., Djelil, M., Djafour, N., Djafour, M. "Calculation of Critical Load for Pure Distortional Buckling of Lipped Channel Columns", Periodica Polytechnica Civil Engineering, 63(4), pp. 1016-1029, 2019 https://doi.org/10.3311/PPci.13244

[14] Hoveidae, N., Rafezy, B. "Global buckling prevention condition of all-steel buckling restrained braces", Journal of Theoretical and Applied Mechanics, 51(4), pp. 891-902, 2013. [online] Available at: https://www.researchgate.net/publication/289352430_Global_ buckling_prevention_condition_of_all-steel_buckling restrained_braces

[15] Iványi, M. "Experiments on Plastic Buckling of Steel Beams", Periodica Polytechnica Civil Engineering, 18(3), pp. 139-167, 1974.

[15] Earls, C. J. "On the inelastic failure of high strength steel I-shaped beams", Journal of Constructional Steel Research, 49(1), pp. 1-24, 1999. https://doi.org/10.1016/S0143-974X(98)00204-1

[16] Yu, C., Schafer, B. W. "Distortional Buckling Tests on ColdFormed Steel Beams", Journal of Structural Engineering, 132(4), pp. 515-528, 2006. https://doi.org/10.1061/(ASCE)0733-9445(2006)132:4(515)

[17] Thomas, S. J., Earls, C. J. "Cross-Sectional Compactness and Bracing Requirements for HPS483W Girders", Journal of Structural Engineering, 129(12), pp. 1569-1583, 2003. https://doi.org/10.1061/(ASCE)0733-9445(2003)129:12(1569)

[18] Hoveidae, N. "Numerical Investigation of Seismic Response of Hybrid Buckling Restrained Braced Frames", Periodica Polytechnica Civil Engineering, 63(1), pp. 130-140, 2019. https://doi.org/10.3311/PPci.12040

[19] Badari, B., Papp, F. "On Design Method of Lateral-torsional Buckling of Beams: State of the Art and a New Proposal for a General Type Design Method", Periodica Polytechnica Civil Engineering, 59(2), pp. 179-192, 2015. https://doi.org/10.3311/PPci.7837

[20] Oszvald, K., Dunai, L. "Effect of corrosion on the buckling of steel angle members-experimental study", Periodica Polytechnica Civil Engineering, 56(2), pp. 175-183, 2012. https://doi.org/10.3311/pp.ci.2012-2.04

[21] Lecce, M., Rasmussen, K. J. "Distortional buckling of cold-formed stainless steel sections: experimental investigation", Journal of Structural Engineering, 132(4), pp. 497-504, 2006. https://doi.org/10.1061/(ASCE)0733-9445(2006)132:4(497)

[22] Lecce, M., Rasmussen, K. "Distortional buckling of cold-formed stainless steel sections: Finite-element modeling and design", Journal of Structural Engineering, 132(4), pp. 505-514, 2006. https://doi.org/10.1061/(ASCE)0733-9445(2006)132:4(505)

[23] Yuan, W. "Nonlinear instability analyses of channel-section beams subjected to minor-axis pure bending", International Journal of Mechanical Sciences, 73, pp. 77-81, 2013. https://doi.org/10.1016/j.ijmecsci.2013.04.011

[24] Niu, S., Rasmussen, K. J., Fan, F. "Distortional-global interaction buckling of stainless steel C-beams: Part I - Experimental investigation", Journal of Constructional Steel Research, 96, pp. 127-139, 2014.

https://doi.org/10.1016/j.jcsr.2014.01.007 
[25] Theofanous, M., Liew, A., Gardner, L. "Experimental study of stainless steel angles and channels in bending", Structures, 4, pp. 80-90, 2015.

https://doi.org/10.1016/j.istruc.2015.10.004

[26] Kumar, N., Sahoo, D. R. "Optimization of lip length and aspect ratio of thin channel sections under minor axes bending", ThinWalled Structures, 100, pp. 158-169, 2016. https://doi.org/10.1016/j.tws.2015.12.015

[27] Mania, R. J., Madeo, A., Zucco, G., Kubiak, T. "Imperfection sensitivity of post-buckling of FML channel section column", ThinWalled Structures, 114, pp. 32-38, 2017. https://doi.org/10.1016/j.tws.2017.01.033

[28] Liang, Y., Zhao, O., Long, Y., Gardner, L. "Stainless steel channel sections under combined compression and minor axis bending Part 1: Experimental study and numerical modelling", Journal of Constructional Steel Research, 152, pp. 154-161, 2019. https://doi.org/10.1016/j.jcsr.2018.03.027

[29] Rezaiee-Pajand, M., Estiri, H. "A Comparison of Large Deflection Analysis of Bending Plates by Dynamic Relaxation", Periodica Polytechnica Civil Engineering, 60(4), pp. 619-645, 2016. https://doi.org/10.3311/PPci.8728

[30] CEN "EN 1993-1-5 Eurocode 3 - Design of steel structures Part 1-5: Plated structural elements", European Committee for Standardization, Brussels, Belgium, 2006.

[31] Gardner, L., Nethercot, D. A. "Designers' Guide to EN 1993-1-1 Eurocode 3: Design of Steel Structures: General Rules and Rules for Buildings", Thomas Telford, London, UK, 2005.

[32] Haaijer, G., Thürlimann, B. "On inelastic buckling in steel", Fritz Engineering Laboratory, Lehigh University, Betlehem, PA, USA, Rep. 22, 1957. [online] Available at: https://preserve.lehigh.edu/ engr-civil-environmental-fritz-lab-reports/1426/

[33] ASTM "ASTM E8/E8M-16a Standard Test Methods for Tension Testing of Metallic Materials", ASTM International, West Conshohocken, PA, USA, 2016. https://doi.org/10.1520/E0008_E0008M-16A

[34] Dassault Systemes "ABAQUS/CAE/Standard (Version 6.8-3)" [computer program] Available at: https://www.3ds.com/support/ hardware-and-software/simulia-system-information/abaqus68-68-extended-functionality/abaqus-68-68-ef-supportedplatforms-products/

[35] Yaman, Z. D., Aktaş, M., Elmas, M. "Investigation of mesh size effect in finite element analysis of minor axis bending $U$ section beams", E-Journal Of New World Sciences Academy Engineering Sciences, 6(1), pp. 225-236, 2011. (In Turkish)

[36] Yaman, Z. D., Eryılmaz, D. M., Aktaş, M., Elmas, M. "Doğrusal olmayan sonlu elemanlar analizinde çelik eğilme elemanlarının geometrik kusurlarının tanımlanması" (Identification of geometric defects of steel bending elements in nonlinear finite element analysis), presented at International Sakarya Earthquake Symposium, Sakarya, Sakarya, Turkey, Oct. 1-2, 2009. (In Turkish)

[37] Macneal, R. H. "A simple quadrilateral shell element", Computers \& Structures, 8(2), pp. 175-183, 1978. https://doi.org/10.1016/0045-7949(78)90020-2
[38] Aktas, M., Earls, C. J. "Minor axis moment-thrust response behavior in steel I-shaped members", Journal of Structural Engineering, 132(7), pp. 1079-1086, 2006.

https://doi.org/10.1061/(ASCE)0733-9445(2006)132:7(1079)

[39] Beale, R. G., Godley, M. H. R., Enjily, V. "A theoretical and experimental investigation into cold-formed channel sections in bending with the unstiffened flanges in compression", Computers \& Structures, 79(26-28), pp. 2403-2411, 2001. https://doi.org/10.1016/S0045-7949(01)00073-6

[40] Nasery, M. M., Hüsem, M., Okur, F. Y., Altunişik, A. C. "Damage effect on experimental modal parameters of haunch strengthened concrete-encased composite column-beam connections", International Journal of Damage Mechanics, 29(2), pp. 297-334, 2019.

https://doi.org/10.1177/1056789519843330

[41] Hüsem, M., Nasery, M. M., Okur, F. Y., Altunişik, A. C. "Experimental evaluation of damage effect on dynamic characteristics of concrete encased composite column-beam connections", Engineering Failure Analysis, 91, pp. 129-150, 2018. https://oi.org/10.1016/j.engfailanal.2018.04.030

[42] Schafer, B. W., Peköz, T. "Computational modeling of coldformed steel: characterizing geometric imperfections and residual stresses", Journal of Constructional Steel Research, 47(3), pp. 193-210, 1998. https://doi.org/10.1016/S0143-974X(98)00007-8

[43] Brescia, M. "Rotation capacity and over strength of steel members for seismic design", PhD Thesis, University of Naples Federico II, 2008. [online] Available at: http://www.fedoa.unina.it/3268/

[44] Joint Committee of the Welding Research Council and the American Society of Civil Engineers "Plastic Design in Steel: A Guide and Commentary", ASCE, New York, NY, USA, 1971.

[45] AISC "Load and Resistance Factor Design Specification for Structural Steel Buildings", American Institute of Steel Construction, Chicago, IL, USA, 1999.

[46] AASHTO "AASHTO- LRFD Bridge Design Specifications", 3rd ed., American Association of State Highway and Transportation Officials, Washington, DC, USA, 2004.

[47] Earls, C. J. "Factors Influencing Ductility in High Performance Steel I-Shaped Beams", In: The 6th International Colloquium Stability \& Ductility of Steel Structures, Timisoara, Romania, 1999, pp. 269-282.

[48] Cardoso, F. S., Zhang, H., Rasmussen, K. J. R., Yan, S. "Reliability calibrations for the design of cold-formed steel portal frames by advanced analysis", Engineering Structures, 182, pp. 164-171, 2019 .

https://doi.org/10.1016/j.engstruct.2018.12.054

[49] Gardner, L., Yun, X. "Description of stress-strain curves for coldformed steels", Construction and Building Materials, 189, pp. 527538, 2018. https://doi.org/10.1016/j.conbuildmat.2018.08.195

[50] Yaman, Z. D. "Investigation of plastic design requirements of u section steel beams subjected to minor axis bending", PhD Thesis, Sakarya University, 2010. 